DOI: 10.19195/0137-1150.163.18

\title{
OLGA SAZONTCHIK
}

Friedrich-Schiller-Universität Jena, Niemcy

olga.sazontchik@uni-jena.de

\section{Булат Окуджава, Мне не нравится мой силуэт..., или несколько размышлений о вкусе поэта}

Стихотворение Булата Окуджавы Мне не нравится мой силуэт... ${ }^{1}$ было впервые опубликовано в его сборнике Милости судьбы в 1993 году2; по некоторым источникам датой его написания считается 1989-й год후 в любом случае, речь идет об одном из поздних произведений поэта 4 .

Стихотворение состоит из 5 строф (I-V), которые могут быть сгруппированы различным образом: 3 [(I \& II) + III] $+2[\mathrm{IV}+\mathrm{V}]$ или 1[I] +2 [II $+\mathrm{IV}]+2[\mathrm{III}+\mathrm{V}]$. В первом случае одна или две строфы описывают некое актуальное состояние, а последняя содержит (риторический) вопрос; при втором варианте группировки первая строфа стихотворения задает палитру обсуждаемых проблем, вторую группу образуют строфы, содержащие констатацию состояния, а третья группа состоит из строф-вопросов; можно показать, что в зависимости от (интуитивно и/или аналитически) предпринимаемого читателем разделения стихотворения на синтаксические и тематические составляющие возникают различные варианты интерпретации произведения в целом. Целью данной статьи является обнаружение и обна-

1 В дальнейшем текст анализируемого стихотворения цитируется по изданию Б. Окуджава, Мне не нравится мой силуэт..., [в:] idem, Чаепитие на Арбате, Москва 1996, с. 511. Тексты остальных стихотворений Окуджавы, кроме специально оговоренных случаев, также цитируются по данному изданию, с указанием заглавия стихотворения и страниц(ы).

2 См. Б. Окуджава, Стихотворения, Москва 2008, с. 457.

3 Cp. сайт Булата Окуджавы, http://www.bokudjava.ru/M_27.html [доступ: 15.07.2015]. Датировка всех цитированных текстов Окуджавы приводится в дальнейшем по данному источнику.

4 О сложности датировки текстов Окуджавы см. С. Бойко, Комментарий, [в:] Б. Окуджава, Стихотворения, Москва 2008, с. 397-401. 
жение механизмов зарождения различных - порой до полной противоположности - смыслов и их обсуждение 5 .

При первом („наивном”) прочтении стихотворение Окуджавы представляет собой критическое высказывание некоего безымянного субъекта о самом себе в сравнении с собственным прошлым: лирическое Я недовольно собственной внешностью (включая одежду), настроением и внутренним состоянием, все воспринимается им как ненужное (в том числе выброшенным на помойку) или отсутствующее (как, например, надежды или любовь), причем лирическое Я не в силах (или: не испытывает желания) ничего изменить, намереваясь „допле[стись] до финала и так”. Summa summarum возникает образ старого и любящего несколько побрюзжать человека, доживающего свой век (,догорающего”) и - ему самому непонятно почему - мучимого, как (ему и читателю) кажется, риторическими вопросами о причинах собственной внутренней неудовлетворенности.

Эта - почти трагическая — трактовка текста только углубляется при учете первичного уровня интертекстуальных связей: для читателя, более или менее знакомого с творчеством Окуджавы, строфы, описывающие актуальное состояние лирического Я, практически полностью составлены из слов-маячков, маркирующих и вызывающих в памяти типичные окуджавские темы и мотивы. Во второй строфе читатель распознает прямую отсылку к известному стихотворению Окуджавы $\mathrm{Cma}$ рый пиджак (1960), ср.:

Я много лет пиджак ношу.

Давно потерся и не нов он.

И я зову к себе портного

и перешить пиджак прошу 6 .

Отказ снова обновить данный предмет одежды становится, таким образом, отказом поэта от образов и идей собственного раннего творчества. Четвертая строфа содержит аллюзии на известный текст Прощание с новогодней елкой $(1966)^{7}$. На эту связь с претекстами указывает и подобной трактовки их полемического отрицания придерживается Н. Богомолов, считающий, что

[п]оэт открыто полемизирует с собою ранним, заставляя себя переосмыслять то, что много лет назад было вложено в стихи. Известно, что Окуджава, хотя и редко говорил об этом, чувствовал несовпадение своих старых стихов с сегодняшними настроения-

5 Продуктивным для дальнейшего анализа представляется использование предложенного Вольфом Шмидом синтеза интуитивного и аналитического методов прочтения текста (см., например, W. Schmid, Analysieren oder deuten? Überlegungen zur Kontroverse zwischen Strukturalismus und Hermeneutik am Beispiel von Čechovs „Nevesta”, „Die Welt der Slawen” № 32, 1987, с. 101-120) и — при обсуждении проблем интертекстуальности — терминологии эквивалентностей на различных уровнях (см., например, W. Schmid, Puškins Prosa in poetischer Lektüre, München 1991, c. 103-170).

${ }^{6}$ Старый пиджак, с. 90.

${ }^{7}$ Прощчание с новогодней ёлкой, с. 230-231. 
ми и потому мог иронизировать над ними, объяснять неуместные толкования и даже отказываться от каких-то строк ${ }^{8}$.

Подобным образом как отрицаемые прочитываются такие неизменно у (раннего) Окуджавы положительно коннотируемые ценности как надежда, вера, любовь, судьба.

Ни в коей мере не подвергая сомнению возможность и обоснованность данных интерпретаций стихотворения Окуджавы („старый усталый поэт” и „поэт, отрицающий самого себя, свое прошлое творчество”), можно, однако, задаться вопросом, насколько исчерпан и исчерпывается ли потенциал интерпретаций на уровне раскрытых выше первичных автоинтертекстуальных связей, другими словами, насколько оправдано завершение аналитического процесса на этом уровне. Неудовлетворительность или недостаточность обсуждаемых до сих пор прочтений проявляется, кроме прочего, в том, что за рамки дискуссии об отношении к собственному творчеству по какому-то неловкому умолчанию, мимоходом выводятся две строфы стихотворения (то есть 40\% текста!), заканчивающиеся вопросительными знаками (третья и пятая).

Исходным пунктом очередного, третьего этапа анализа могут послужить следующие общие соображения: с одной стороны, необходимо учесть ту особую важность, которая придается при анализе началу (и концу) текста (см. второй вариант группировки строф), с другой стороны, привлечь к рассмотрению мысль о том, что содержащиеся в тексте отрицания являются указанием на возможность (и, в известной степени, внутреннюю необходимость) (авто)интертекстуального его прочтения 9 . С обеих точек зрения, необходимо еще раз обратиться к началу стихотворения, его первой строфе. В тексте Окуджавы можно найти большое количество отрицаний, не только эксплицитных (например, в форме частиц не и ни), но и имплицитных, причем последние, кроме прочего, проявляются в форме противопоставлений $(a$ ведb, но), кодируются на уровне звуковых повторов или подчеркиваются использованием тавтологических выражений. Первая строфа, с одной стороны, обращает на себя внимание как пример необычного сгущения, примечательной концентрации всех упомянутых выше признаков интертекстуальности и средств ее актуализации:

Мне не нравится мой силуэт:

невпопад как-то скомкан и скроен.

${ }^{8}$ Н. Богомолов, Так ли просты стихи Окуджавы?, [в:] idem, От Пушкина до Кибирова. Статьи о русской литературе, преимущественно поэзии, Москва 2004, с. 420.

${ }^{9} \mathrm{Cp}$. мысль об отрицаниях как указаниях на интертекстуальность per se, например, у Н. Фатеева, Интертекст в мире текстов. Контрапункт интертекстуальности, Москва 2012, с. 126 сл. Необходимо подчеркнуть, что (авто)интертекстуальные связи разного рода служат основой дальнейших рассуждений, но не являются как таковые (их классификация и пр.) предметом анализа в данной статье. 
А ведь мальчик был ладен и строен...

И надежды на лучшее нет ${ }^{10}$.

Строфа содержит, кроме многочисленных *не/*ен, противопоставление ( $($ ведb), а также дополнительно усиленное неопределенным наречием „както” наречие „невпопад” (с семантикой неопределенности) и прижившееся в языке, но остраняемое в поэтическом тексте контекстом и потому заново воспринимаемое как семантически избыточное выражение „надежды [на лучшее] нет”. Из „отрицающего” (*не/-ен) звукового ряда, равно как и из подчеркнуто повседневного ряда лексического, однако, выбивается помещенное в конец (sic!) первого стиха иностранное слово „силуэт”.

Понятие силуэт многозначно. С одной стороны, силуэт (от фр. silhouette, по имени французского министра 18 -го века ${ }^{11}$ ) - это вид и прием графического искусства, обычно вырезанное из бумаги плоскостное изображение чего- или кого-либо; в более общем смысле речь идет об абрисе, общем контуре, внешнем очертании. В данном случае, как представляется, особое внимание должно быть уделено также необычному сочетанию „мой силуэт", представляющему собой как физическое явление относительно сложную структуру отражений, а как поэтический прием - оригинальную форму (само-)рефлексии ${ }^{12}$. При дальнейшем анализе эти значения слова $c u$ луэт будут обозначаться соответственно как „силуэтные линии” бумага, внешность и мой. Можно показать, что текст Окуджавы предполагает и позволяет прочтение по всем трем семантическим линиям, причем многозначность понятия сохраняется и остается неразрешимой.

Берущая свое начало в первой строфе силуэтная линия бумага прослеживается вплоть до последнего стиха, причем действия по отношению к бумаге, на первый взгляд, связаны с ее уничтожением: ее комкают, рвут, марают и - благодаря непосредственному соседству с метафорой огня (возможно) сжигают:

силуэт $[. .$.$] невпопад как-то скомкан [. .$.

Но тогда отчего, отчего

рву листы и бумагу мараю?

Не сгорел - только все догораю

и молчанья боюсь своего?

10 Выделения в цитатах, кроме специально оговоренных случаев, принадлежат автору статьи - O.S.

${ }^{11}$ Ср. Словарь иностранных слов, ред. А.Г. Спиркин, И.А. Акчурин, Р.С. Карпинский, Москва 1988, с. 454.

12 В отличие, например, от рассмотрения отражения в зеркале или тени на стене, случай (в физическом смысле) возникновения и восприятия собственного силуэта относительно редок. Использование Окуджавой понятия силуэт (в прозе и поэзии) как особой точки зрения, специфического приема остранения может послужить предметом рассмотрения отдельной статьи.

Slavica Wratislaviensia 163, 2016

(C) for this edition by CNS 
Подобным образом ведет себя и силуэтная линия внешность: скроенный невпопад силуэт, материальным воплощением которого становится старый пиджак, обречен на дальнейшее истирание, донашивание, прозябание до финала, конца, ср.:

силуэт [...] невпопад как-то [...] скроен. [...]

Поистерся мой старый пиджак,

но уже не зову я портного:

перекройки не выдержать снова -

доплетусь до финала и так.

Таким образом, линии как бумажного, так и внешнего силуэтов метафорически углубляют те интерпретации стихотворения, о которых речь шла выше, развивая, в конечном итоге, темы старости, уничтожения и смерти.

Силуэтную линию мой (поддерживаемую на грамматическом уровне многочисленными местоимениями и глаголами 1 лица единственного чис$л^{13}$ ) можно рассматривать как вариант эксплицитной отсылки к Я не только лирического субъекта, но и - принимая во внимание уже подвергнутые обсуждению автоинтертекстуальные связи - самого автора. Такой подход позволяет проанализировать эти связи еще раз, с несколько иной точки зрения, а именно задавшись вопросом, что означают те или иные темы или мотивы не только в одном конкретном аллюдируемом тексте, но в творчестве Окуджавы в целом; можно сказать, что речь в данном случае будет идти об анализе текста на уровне вторичных эквивалентностей.

Как уже отмечалось выше, вторая строфа стихотворения прямо отсылает к конкретному тексту 1960- года, и ее амбивалентное прочтение (прямое или метафорическое, предмет одежды или поэт) поддерживает темы старости и приближающегося конца. Однако мотив пиджака (в том числе как части костюма) встречается у Окуджавы часто и в весьма определенной коннотации. Уже в Старом пиджаке ${ }^{14}$ перекраивание пиджака связывается - пусть недоверчиво и гипотетически (с оговоркой „как бы не так”) - с началом новой жизни, возрождением верь в любовь (,едва ли я пиджак примерю - // опять в твою любовь поверю...”). Пиджак, и непременно прежний, является атрибутом мирной жизни (до войны и после войны), то есть противостоит шинели как примете войны:

Затихнет шрапнель, и начнется апрель.

На прежний пиджак поменяю шинель (1969) ${ }^{15}$.

13 Это подчеркнутое единообразие, исключительность и эксплицитность использования 1-го лица не разумеются сами собой; лирическое Я Окуджавы часто говорит о себе в третьем лице, в том числе и в связи с понятием силуэт, ср.: „Вы [...] погрустите хотя бы, увидев, как сходит на нет// серый, чужой, старомодный, сутулый его силуэт" (Чmo-mo cblночек мой уединением стал тяготиться..., с. 452).

14 Старый пиджак, с. 90.

15 Затихнет шрапнель, и начнется апрель..., с. 142. Здесь и далее указание на предполагаемую дату написание текста — при всей ее проблематичности (см. сноску 4) - необходимо для некоторых последующих рассуждений.

Slavica Wratislaviensia 163, 2016

(C) for this edition by CNS 
(Потертый) костюм становится признаком самоидентификации („Потертые костюмы сидят на нас прилично..."

На мне костюмчик серый-серый, совсем как серая шинель.

И выхожу я на эстраду

и тихим голосом пою ${ }^{17}(1959)$.

и признаком художника (артиста, творца) вообще:

Ах, флейтист, флейтист в старом пиджаке,

с флейтою послушною в руке (1969).

Еще покуда в честь нее высокий хор звучит хвалебно, и музыканты все в парадных пиджаках $(1979)^{18}$.

Таким образом, тема (старого) пиджака непосредственно связана с образом художника-творца, затрагивает проблемы веры и неверия, в том числе в новую (или старую) любовь.

Сходным образом могут быть выявлены пограничные темы четвертой строфы, с содержащейся в ней отсылкой к Прощанию с новогодней ёлкой (1966). Тема кониа, введенная подчеркнуто просторечным мотивом помой$\kappa и$, пересекается в поле мой с мотивами Нового года как символа начала, хода времени, надежды на перемены, ср.

Вот и январь накатил-налетел,// бешеный как электричка. (1966) vs.

На смену декабрям// приходят январи ${ }^{19}$ (1959).

Одновременно актуализируются мотивы огня и любви, а также верь (и религии), ср.:

И в суете тебя сняли с креста,

и воскресенья не будет. [...]

Ель моя, Ель, словно Спас-на-крови,

твой силуэт отдаленный,

будто бы след удивленной любви,

вспьхнувшей, неутоленной ${ }^{20}(1966)$.

Тема Cnaca, в свою очередь, привносит тему детства и молодости, иногда вторично отрицаемых упоминанием произошедших перемен:

У Спаса на Кружке забыто наше детство

Что видится теперь в раскрытое окно?

Все меньше мест в Москве, где можно нам погреться, все больше мест в Москве, где пусто и темно ${ }^{21}$ (1979).

\footnotetext{
16 Прощзание с Польшей, с. 208.

17 На мне костюмчик серый-серый..., с. 65.

18 Старый флейтист, с. 180 и Еще один романс, с. 354.

19 Прощание с новогодней ёлкой, с. 230 и Неистов и упрям..., с. 10.

20 Прощяание с новогодней ёлкой, с. 231.

21 У Спаса на Кружке забыто наше детство..., с. 346.
} 
Возникает сложный тематический узел, в котором причудливо скрещиваются отвержение и утверждение, старость и молодость, вера и безверие, начало и конец. Предложенные прежними интерпретациями как решение отрицание, полемика с содержанием прошлого творчества, ставят, очевидно, по силуэтной линии мой больше вопросов, чем дают ответов.

Бросающейся в глаза особенностями второй и четвертой строф является сравнительно косвенное, опосредствованное обозначение и обсуждение проблем. Так, субъектами предложений являются ель, храм, пиджак; часты безличные предложения или эллиптические конструкции (что, кроме прочего, обуславливает амбивалентность прочтения, как, например, в случае c „перекройки не выдержать” - поэту или пиджаку?), проблемы ставятся путем апеллирования к прежним текстам и отрицания предыдущих решений (например, „не выдержать снова” и пр.). Этой имплицитной постановкой вопросов они отличаются от строф, до сих пор несколько обделенные вниманием при анализе, а именно третьей и пятой:

Но тогда почему, почему, по капризу какому такому ничего не прощаю другому и перчатку швыряю ему? [...]

Но тогда отчего, отчего рву листы и бумагу мараю? Не сгорел — только все догораю и молчанья боюсь своего?

По контрасту к описательным, констатирующим актуальное состояние лирического Я второй и четвертой, третья и пятая строфы эксплицитно содержат риторические, то есть - на первый взгляд - оставляемые без ответа, вопросы. Кроме того, эти строфы отличаются повышенной степенью присутствия лирического Я (все действия обозначены глаголами в первом лице единственного числа настоящего времени, ср. рву, мараю, горю, швыряю). Этим на грамматическом уровне усиливается прямое их противопоставление остальным строфам (с иными субъектами действия, пришедшими из прошлого творчества, или безличными предложениями, см. выше), которое эксплицитно обозначается анаферическими вопросительными конструкциями „,[н]о тогда почему” и „,[н]о тогда отчего".

В результате возникает некая конструкция „отрицания отрицания”, то есть постановки под вопрос вывода о неизбежности и неотвратимости смерти, финала, конца, уничтожения как логического результата рассмотренных выше сюжетных (силуэтных) линий и вариантов прочтения. Этот очередной виток размышлений лирического Я находит свое выражение в новой совокупности поднимаемых и/или аллюдируемых в данных стро- 
фах мотивов и тем, вводимых на этот раз (и снова: в отличие от остальных строф) глаголами, то есть более „динамичной”, активной частью речи, непосредственно обозначающей действие.

Действие третьей строфы, „швырять (бросать) перчатку” в сочетании c ,(не)прощением (обид)”, является классической метафорой вызова на дуэль и в окуджавском творчестве, то есть по силуэтной линии мой - эпитетом, стандартным атрибутом жизни художника и смерти как ее неотъемлемой части. Такое восприятие поэтом дуэли может быть усилено упоминанием конкретных имен, ср.

Берегите нас < поэтов $>$ с грехами, с радостью и без.

Где-то, юный и прекрасный, ходит наш Дантес.

Он минувшие проклятья не успел забыть, но велит ему призванье пулю в ствол забить 22 (1960-1961).

...вдруг Лермонтов возник передо мной [...]

— Мартынов - что... -

он мне сказал с улыбкой. -

Он невиновен.

Я его простил ${ }^{23}(1965)$.

И спешит Грибоедов навстречу судьбе,

близоруко прищурив глаза ${ }^{24}(1965)$.

Пушкин, Пушкин, счет обидам -

очень грустная статья.

Но неужто быть убитым -

привилегия твоя? ${ }^{25}$ (1969)

или выражено обобщенно:

...по улице этой,

где старинные стынут дома,

в поединках сходились поэты... ${ }^{26}$ (1959)

Не все ль равно, что нас сведет в могилу — пуля иль простуда? ${ }^{27}$ (1974)

В последнем случае обобщение понимания смерти как (говоря словами другого поэта) „принимаемой” части жизни упоминанием банальной проcтудbl 'переведено' на язык повседневности.

Введенная таким образом, в связи с мотивом дуэли, тема прощения представляет собой еще одно семантическое поле в творчестве Окуджавы,

\footnotetext{
22 Берегите нас, поэтов.., с. 164.

23 Bстреча, c. 217.

${ }^{24}$ Грибоедов в Цинандали, с. 219.

${ }^{25}$ На углу у гастронома..., с. 248.

26 ...И когда удивительно близко..., с. 18.

${ }^{27}$ На смерть Бориса Балтера, с. 339.
} 
которое прямо связывается им с творчеством. Умение простить является высшим из искусств, ср.

Искусство всё простить и жажда жить недосягаемое совершенство ${ }^{28}$ (1989).

Оно рассматривается как свойство, функция поэта, сближающая его с Богом:
„Прощай...”
Прощаю, чтоб не вышло боком.
Сосуд добра до дна не исчерпать.
Я чувствую себя последним богом,
единственным умеющим прощать 29 (1964).

Таким образом, обозначенное первыми двумя строфами отрицание собственного авторского прошлого автоинтертекстуальными связями третьей строфы переводится на иной уровень, на уровень размышлений о сути и назначении поэтического творчества вообще, причем размышлений, скоpee, жизнеутверждающих.

На уровне вторичных эквивалентностей, на силуэтной линии мой, иную коннотацию получают поверхностно воспринимаемые как метафоры разрушения и уничтожения действия пятой строфы (рвать, марать, гореть). В поэтическом мире Окуджавы глаголы рвать и марать (листы или бумагу) неизменно связываются с описанием творческого процесса:

Пишу роман. Тетрадка в клеточку.

Пишу роман. Страницы рву ${ }^{30}$ (1989).

Их седой командир, весь в коросте и рвани, пишет письма домой на глухом барабане, позабыв все слова, он марает листы. [...]

Их седой режиссер, обалдевший от брани, пишет пьеску на порванном вдрызг барабане, позабыв все слова, он марает листы... ${ }^{31}(1964)$

Кроме того, выражение марать (бумагу) является своеобразной, 'двухслойной' ссылкой на Пушкина, то есть как на собственное стихотворение Окуджавы о поэте:

Он умел бумагу марать под треск свечки! $!^{22}(1967)$

\footnotetext{
28 В больнице медленно течет река часов..., с. 455.

${ }^{29}$ Прощзание с осенью, с. 197.

${ }^{30}$ Пишу роман. Тетрадка в клеточку..., с. 458.

${ }^{31}$ Из окна вагона, с. 203.

${ }^{32}$ Счастливчик Пушкин, с. 158.
} 
так и на самого поэта, в словаре которого марать - глагол, чаще всего встречающийся при упоминании (собственного) творчества ${ }^{33}$, в том числе в письмах:

Я провожу моё время в том, что мараю бумагу и злюсь ${ }^{34}$

или (многократно) в романе Евгений Онегин, например:

\author{
Всегда я рад заметить разность \\ Между Онегиным и мной, \\ Чтобы насмешливый читатель [...] \\ Сличая здесь мои черты, \\ Не повторял потом безбожно, \\ Что намарал я свой портрет, \\ Как Байрон, гордости поэт... (EO 1, LVI $)^{35}$ \\ Перу старинной нет охоты \\ Марать летучие листын... (EO 6, XLIII) \\ Проснулся он; ему приносят \\ Письмо: князь N. покорно просит \\ Его на вечер. „Боже! к ней!.. \\ О буду, буду!" и скорей \\ Марает он ответ учтивый (ЕО 8, XXI).
}

То есть из заложенной в глаголах первичной семантики уничтожения на уровне вторичных эквивалентностей (в силуэтной линии мой) возникает тема творчества, созидания.

Мотивы огня, горения и сгорания также появляются уже в одном из первых стихотворений Окуджавы и проходят через все его творчество. С огнем сравниваются любовь и исполненная смысла жизнь:

Прожить лета б дотла,

а там пускай ведут

за все твои дела

на самый страшный суд ${ }^{36}$ (1959).

Затянулся наш роман.

Он затянулся в узелок, горит он — не сгорает... ${ }^{37}$ (1961)

33 Согласно Словарю языка Пушкина, этот глагол используется Пушкиным в значении „Писать начерно, чернить и исправлять написанное, рисовать”, то есть для описания творческого процесса, в 11 случаях из 21, ср. Словарь языка Пушкина, т. 2, ред. В. Виноградов, Москва 1957, с. $541-542$

34 А.С. Пушкин, Пушикин - Н.Н. Гончаровой, 11 октября 1830 г., из Болдина в Москву, [в:] idem, Полное собрание сочинений в 10 m., т. 10, Москва 1962-1966, с. 310.

35 Ссылка на Евгения Онегина (ЕО) дается указанием на главу романа и строфу, для облегчения ориентации в произвольном издании произведения.

${ }^{36}$ Неистов и упрям..., с. 10.

37 Чудесный вальс, с. 115.

Slavica Wratislaviensia 163, 2016

(C) for this edition by CNS 
Главное - это сгорать и, сгорая,

не сокрушаться о том ${ }^{38}$ (1964).

Поэт проходит сквозь разрушительный огонь войны (пекло), из которого - и это подчеркивается - ему удается вылйти:

Я выжил.

Я из пекла вышел.

Там не оставил ничего ${ }^{39}$ (1967).

Нас ждет огонь смертельный, и все ж бессилен он ${ }^{40}(1969)$.

Поздравьте меня, дорогая: я рад, что остался в живых, сгорая в преддверии рая средь маршалов и рядовых, когда они шумной толпою, в сиянии огненных стрел, влекли и меня за собою... Я счастлив, что там не сгорел ${ }^{41}$ (1985).

Выжсиванию в пекле (войны) придается особый смысл, оно воспринимается как предназначение, заключающееся в творческой переработке и осмыслении прожитого:

И так все сошлось, дорогая: наверно, я там не сгорел, чтоб выкрикнуть здесь, догорая, про то, что другой не успел ${ }^{42}$ (1985).

Именно пламя, огонь становятся у Окуджавы метафорой любого творческого процесса, в том числе собственного:

Горит пламя, не чадит, надолго ли хватит?

Она меня не щадит -

тратит меня, тратит ${ }^{43}(1960)$.

Уж целый лист почти совсем готов, и вдруг как будто прозреваю: как нищ и беден мой улов, не те цветы ищу я и срываю.

И жар ловлю не от того огня, и лгу по мелочам природе... ${ }^{44}(1987)$

Также при упоминании иных поэтов речь часто заходит об огне и сгорании: Пушкин „умел бумагу марать // под треск свечки!”45 (1967), Владимир

\footnotetext{
${ }^{38}$ Как научиться рисовать, с. 188.

39 Путешествие в памяти, с. 234.

40 Белорусский вокзал, с. 240.

41 Поздравьте меня, дорогая..., с. 399.

42 Ibidem.

43 Горит пламя, не чадит..., с. 62.

44 Работа, c. 372.

45 Счастливчик Пушкин, с. 158.
} 
Высоцкий „не к сроку свечу затушил”46 (1980), а поэт вообще „[д]огорает, прощения просит,47 (1986). Таким образом, (требование) сгорать является у Окуджавы основной характеристикой любого творчества, мерилом его качества, истинности:

Главное - это сгорать и, сгорая, не сокрушаться о том ${ }^{48}(1964)$.

Ты так играешь, так играешь, как будто медленно сгораешь. Но что-то есть в твоем огне, еще неведомое мне ${ }^{49}(1964)$.

Карандаш желает истину знать. И больше ничего. [...] И, пока недолго длящийся жизни путь к концу лежит, грифелек его дымящийся за добычею бежит ${ }^{50}(1969)$.

Музыкант играл на скрипке — я в глаза ему глядел. [...] Да еще ведь надо в душу к нам проникнуть и зажечь... А чего с ней церемониться? Чего ее беречь? [...] А душа, уж это точно, ежели обожжена, справедливей, милосерднее и праведней она ${ }^{51}$ (1983).

Пусть труба, сынок, мелодию сыграет...

Что из сердца вышло - быстро не сгорает ${ }^{52}$ (1985).

И вот Вы запели тот старый романс, и пламень тревоги, как свечка, угас.

А надо ли было, чтоб сник этот пламень тревоги?

И вот Вы запели тот старый романс, но пламень тревоги, который угас, опять разгорелся, как поздний костер у дороги ${ }^{53}$ (1985).

Живопись, музыка, пение - все оказывается лишь бесконечным, вневременным сгоранием художника (становящимся неопалимою купиною), зажигающим и обжигающим душу и делающей ее „справедливей, милосерд-

\footnotetext{
46 О Володе Высоиком, с. 353.

47 У поэта соперников нету..., с. 361.

48 Как научиться рисовать, с. 188.

49 Надежда, белою рукою..., с. 216.

50 Карандаш желает истину..., с. 226.

${ }^{51}$ Музыкант, с. 406.

52 В день рождения подарок..., с. 411.

53 Памяти Обуховой, с. 429.
} 
нее и праведней”. Вся его (художника) жизнь приобретает смысл лишь в приобщении к этому вечному огню, в причастности к его поддержанию, в готовности принесения себя ему в жертву, ср.:

Они сидят в кружок под низким потолком.

Освистаны их речи и манеры.

Но вечные стихи затвержены тайком,

и сундучок сколочен из фанеры.

Наверно, есть резон в исписанных листах, в затверженных местах и в горстке пепла...

О, как сидят они с улыбкой на устах,

прислушиваясь к выкрикам из пекла! ${ }^{54}$ (1982)

Для тесного круга отверженных (освистанных) и причастных, затвердивших „вечные” стихи и этим спасших их от уничтожения, способных с улыбкой бесстрашия прислушиваться к пеклу, существует лишь один страх - страх перед собственным (творческим) молчанием, страх не гореть, но догореть.

Таким образом, следование силуэтной линии мой (или, другими словами, анализ стихотворения „Мне не нравится мой силуэт...” в том числе и на уровне скрытых и открываемых в нем вторичных эквивалентностей), позволяет расширить диапазон затронутых в нем проблем и углубить их понимание. Безусловно, стихотворение представляет собой автоинтертекстуальную разработку темы старости поэта: обращаясь к своему прежнему творчеству, поэт подвергает сомнению актуальность для себя (сегодняшнего) затронутых в нем тем. Однако он не отрицает ни их общей важности, ни процесса творчества как такового. Более того, творчество - по Окуджаве - не знает возраста, то есть сущность его не меняется со временем и во времени. Попытка определить вектор развития тем, связанных с размышлениями поэта над сущностью творчества, приводит к заключению, что он обращается в точку. У Окуджавы, говоря словами Евтушенко, „нет лет”, то есть сосуществующими, одно-, со- или вневременными оказываются не только его собственные стихи ${ }^{55}$, но и тексты его предшественников и современников (поэтов, художников, музыкантов), а потому Моцарт непринужденно соседствует с Высоцким, Лермонтов с Обуховой, Балтер с Пушкиным и т.д. Риторические, на первый взгляд, вопросы являются (на этом

${ }^{54}$ Прогулки фрайеров, с. 380.

55 А потому приведенные выше указания на даты создания отдельных стихотворений только способствуют осмыслению того факта, насколько эти даты - по крайнем мере, при рассмотрении текстов, связанных с данной тематикой - не важны, насколько постоянно во времени восприятие и понимание обсуждаемых Окуджавой проблем. 
уровне рассмотрения) ответом: бояться следует не смерти и не старости, но только собственного молчания, и молчание еще живущих (то есть: нетворение) страшнее их собственной смерти.

\section{Библиография}

Schmid W., Analysieren oder deuten? Überlegungen zur Kontroverse zwischen Strukturalismus und Hermeneutik am Beispiel von Čechovs „Nevesta“, „Die Welt der Slawen“ 1987, № 32. Schmid W., Puškins Prosa in poetischer Lektüre, München 1991.

Богомолов Н., Так ли просты стихи Окуджавы?, [в:] От Пушкина до Кибирова. Статьи о русской литературе, преимущественно поэзии, Москва 2004.

Бойко С., Комментарии, [в:] Б. Окуджава, Стихотворения, Москва 2008.

Окуджава Б., Стихотворения, Москва 2008.

Окуджава Б., Чаепитие на Арбате, Москва 1996.

Пушкин А.С., Пушкин - Н.Н. Гончаровой, 11 октября 1830 г., из Болдина в Москву, [в:] idem, Полное собрание сочинений в 10 томах, т. 10, Москва 1962-1966.

Сайт Булата Окуджавы, http://www.bokudjava.ru/.

Словарь иностранных слов, ред. А.Г. Спиркин, И.А. Акчурин, Р.С. Карпинский, Москва 1988.

Словарь языка Пушкина, т. 2, ред. В. Виноградов, Москва 1957.

Фатеева Н., Интертекст в мире текстов. Контрапункт интертекстуальности, Москва 2012.

\section{Bulat Okudzhava, Mne Ne Nravitsya Moy Siluet... (I Don't Like My Silhouette...), or some reflections upon the taste of poet}

\section{Summary}

The article deals with one of late poems by Bulat Okudzhava (Mne ne nravitsja moj siluet...), in which in the first place various auto-intertextual associations are reviewed. Although in a superficial embodiment of an aged poet who is dissatisfied with himself a clear bitter reckoning with his own work can be perceived, the outcome, however, which can be discerned on the next level, is a deeper and by all means positive conception of the sense of life of an artist, hardly correlating to time (and thus aging).

Keywords: Bulat Okudzhava, auto-intertextual associations, aging 


\section{Bulat Okudžava, Mne Ne Nravitsya Moy Siluet..., ili nekoliko misli o ukusu pjesnika}

\section{Rezime}

Članak razmatra jednu od kasnijih pjesama Bulata Okudžave Mne ne nravitsja moj siluet..., pri čemu se prije svega spominju razne autointertekstualne veze. Rezultat toga je, iako se u površnom prikazu ostarjelog i samim sobom nezadovoljnog pjesnika može razaznati očit gorak obračun s vlastitim stvaralačkim radom, na drugoj se, višoj razini može naći puno dublja i u svakom slučaju pozitivna predodžba smisla života jednog umjetnika s neznatnim osvrtom na vrijeme (i starenje).

Ključne riječe: Okudžava, autointertekstualne veze, starenje 